\title{
Water as an independent taste modality
}

\author{
Andrew M. Rosen, Andre T. Roussin and Patricia M. Di Lorenzo*
}

Department of Psychology, Binghamton University, Binghamton, NY, USA

Edited by:

L. Ashley Blackshaw, University of Adelaide, Australia

\section{Reviewed by:}

L. Ashley Blackshaw, University of

Adelaide, Australia

Richard L. Young, University of

Adelaide, Australia

\section{${ }^{*}$ Correspondence:}

Patricia M. Di Lorenzo, Department of

Psychology, Binghamton University,

Box 6000, Binghamton,

NY 13902-6000, USA.

e-mail: diloren@binghamton.edu
To qualify as a "basic" taste quality or modality, defined as a group of chemicals that taste alike, three empirical benchmarks have commonly been used. The first is that a candidate group of tastants must have a dedicated transduction mechanism in the peripheral nervous system. The second is that the tastants evoke physiological responses in dedicated afferent taste nerves innervating the oropharyngeal cavity. Last, the taste stimuli evoke activity in central gustatory neurons, some of which may respond only to that group of tastants. Here we argue that water may also be an independent taste modality. This argument is based on the identification of a water dedicated transduction mechanism in the peripheral nervous system, water responsive fibers of the peripheral taste nerves and the observation of water responsive neurons in all gustatory regions within the central nervous system. We have described electrophysiological responses from single neurons in nucleus of the solitary tract (NTS) and parabrachial nucleus of the pons, respectively the first two central relay nuclei in the rodent brainstem, to water presented as a taste stimulus in anesthetized rats. Responses to water were in some cases as robust as responses to other taste qualities and sometimes occurred in the absence of responses to other tastants. Both excitatory and inhibitory responses were observed. Also, the temporal features of the water response resembled those of other taste responses. We argue that water may constitute an independent taste modality that is processed by dedicated neural channels at all levels of the gustatory neuraxis. Water-dedicated neurons in the brainstem may constitute key elements in the regulatory system for fluid in the body, i.e., thirst, and as part of the swallowing reflex circuitry.

Keywords: taste, gustatory, water, nucleus of the solitary tract, parabrachial nucleus of the pons

\section{INTRODUCTION}

Taste is a vital sensory process that facilitates the ingestion of nutritive substances and the avoidance of toxins. It is not surprising, then, that the perception of taste stimuli is highly informed by the homeostatic state of the organism (Jacobs et al., 1988; Morton et al., 2006) as well as prior experiences with appetitive and aversive stimuli (Chang and Scott, 1984; McCaughey et al., 1997). Physiological processing of taste stimuli begins with transduction at the level of taste receptor cells distributed throughout the oropharyngeal cavity and extends across a network of central neural structures. The sensory domain of the taste system can be divided into a finite number of qualities or modalities, defined as a group of chemicals that produce similar taste sensations and which are psychophysically independent of other taste qualities. Historically, psychophysicists defined four basic taste qualities: sweet, sour, bitter, and salty. Recently, however, the designation of a fifth quality, umami (savory), has been supported by genetic and physiological data from peripheral taste cells (e.g., Zhao et al., 2003). The designation of discrete taste modalities rests on physiological evidence from every level of the nervous system and bears important functional implications for the homeostatic and hedonic mediation of nutrient intake and toxin avoidance.

Though it is well known that water (or hypo-osmolarity) evokes a unique taste sensation in insects (Evans and Mellon Jr., 1962; Inoshita and Tanimura, 2006), it is perhaps surprising that water has not heretofore been shown to evoke a distinct taste quality in mammals (Bartoshuk, 1974). This, despite substantial physiological evidence showing that there are neurons that respond to water at every level of the gustatory neuraxis. Many investigators who have described these water responses have assumed that they are due to somatosensory or thermal stimulation; however, here we show responses to water that cannot be accounted for by these mechanisms. We will therefore argue that water constitutes an independent taste modality, whose perception is critical for life.

The objectives of the current investigation were to: (1) describe the neural responsivity to water presented as a taste stimulus in cells of the nucleus of the solitary tract (NTS) and parabrachial nucleus of the pons $(\mathrm{PbN})$ and $(2)$ describe converging evidence that water is an independent taste modality. We characterized four different water-responsive cell types in the NTS and $\mathrm{PbN}$ of the rat. Most notably, we observed "water best" cells that responded more vigorously to water than to any other taste stimulus. We argue that the classification of water as an independent taste modality is supported by physiological evidence and has important implications for taste-mediated regulation of ingestive behavior.

\section{MATERIALS AND METHODS SUBJECTS}

Data from 108 male Sprague-Dawley rats $(350-450$ g) were included. Rats were given unrestricted access to food and were paired housed with a 12-h light-dark schedule. Animal care was in accord with the requirements of the Institutional Animal Care 
and Use Committee of Binghamton University. Data from NTS cells were obtained from two previously published investigations of taste processing (Roussin et al., 2008; Rosen and Di Lorenzo, 2009); data from the $\mathrm{PbN}$ are new.

\section{SURGERY}

Prior to surgery, rats were anesthetized with urethane $(1.5 \mathrm{~g} / \mathrm{kg}$, i.p., administered in two doses, $20 \mathrm{~min}$ apart). Some animals were given a third intraperitoneal injection of pentobarbital (Nembutal, $25 \mathrm{mg} / \mathrm{kg})$. Body temperature was maintained at $35-37^{\circ} \mathrm{C}$ with a rectal thermistor probe connected to a heating pad (FHC, Inc., Bowdoinham, ME, USA).

Animals were tracheostomized to facilitate breathing during stimulus delivery. The head was mounted in a stereotaxic instrument with the upper incisor bar positioned $5 \mathrm{~mm}$ below the interaural line. Skin and fascia were removed and a non-traumatic head holder was secured to the skull with stainless steel screws and dental cement. The occipital bone and meninges were removed. In the NTS surgeries, the posterior cerebellum was gently aspirated to expose the underlying medulla. In the $\mathrm{PbN}$ surgeries, only the portion of the cerebellum overlying the obex was aspirated.

\section{TASTE STIMULI AND STIMULUS DELIVERY}

Taste stimuli consisted of $0.1 \mathrm{M} \mathrm{NaCl}, 0.01 \mathrm{M} \mathrm{HCl}, 0.01 \mathrm{M}$ quinine, and $0.5 \mathrm{M}$ sucrose. Concentrations have been shown to elicit half-maximal potentials in the CT nerve of the rat (Ganchrow and Erickson, 1970; Ogawa et al., 1974). Taste stimuli were made from reagent-grade chemicals dissolved in distilled water and were delivered at room temperature. Water was presented both before and after taste stimuli and responses to it were analyzed separately as described below.

The stimulus delivery system consisted of stimulus-filled reservoirs pressurized with compressed air and connected via polyethylene tubing to perforated stainless steel tubes placed in the mouth. Fluid delivery was controlled by computer activation of a solenoid valve interposed between the reservoir and the tongue. Stimuli were delivered at a flow rate of $5 \mathrm{ml} / \mathrm{s}$. The taste solution bathed the whole mouth; this was verified by application of methylene blue through the system. Each stimulus trial consisted of $10 \mathrm{~s}$ spontaneous activity, $10 \mathrm{~s}$ of distilled water, $5 \mathrm{~s}$ of tastant, $5 \mathrm{~s}$ pause, and $20 \mathrm{~s}$ of a distilled water rinse. Spontaneous activity was defined as the firing rate during the initial $5 \mathrm{~s}$ of the trial when no stimulus (tastant or water) was present in the mouth. The inter-trial interval was $2 \mathrm{~min}$. Stimuli were presented in repeated trials for as long as the cell remained well isolated. For any given stimulus, all other stimuli were presented before it was repeated.

\section{ELECTROPHYSIOLOGICAL RECORDING}

Electrophysiological recordings were conducted with etched tungsten microelectrodes (18-20 M $\Omega, 1 \mathrm{~V}$ at $1 \mathrm{kHz}$; FHC, Inc., Bowdoinham, ME, USA). For NTS recordings, the electrode was lowered into the caudal medulla above the rostral NTS located $2.7 \mathrm{~mm}$ anterior and $1.8 \mathrm{~mm}$ lateral the obex and $\sim 1.0 \mathrm{~mm}$ below the dorsal surface of the brainstem. For $\mathrm{PbN}$ recordings, the electrode was lowered through the cerebellum above the pons located $5.4 \mathrm{~mm}$ anterior and $1.8 \mathrm{~mm}$ lateral to the obex and 5-6 $\mathrm{mm}$ below the cerebellar surface. Electrophysiological activity was digitized with an analog-to-digital interface (Model 1401, Cambridge Electronic Designs, Cambridge, UK) and was processed with Spike2 software (Cambridge Electronic Designs, Cambridge, UK). The signal was amplified (Model P511, Grass Technologies, West Warwick, RI, USA) and monitored online with a speaker, oscilloscope and Spike2 software. Single cells were identified by periodically delivering a $0.1-\mathrm{M} \mathrm{NaCl}$ solution followed by a water rinse as the electrode was slowly lowered through the brain. Cell isolation was based on the consistency of the waveform shape using template matching and principal component analysis. A signal-to-noise ratio of 3:1 was required for cell isolation. Isolated cells were tested with the exemplars of the four basic taste qualities yielding the "response profile" of the cell, defined as the relative response rates across tastants. Water was presented before tastant delivery and $5 \mathrm{~s}$ after tastant delivery. This allowed the assessment of tastant-mediated alteration of the water response. The cell was tested for as long as it remained isolated allowing for multiple presentations of the same stimulus. The precise timing of each spike ( $1 \mathrm{~ms}$ precision) was calculated with respect to the onset of each stimulus delivery, including water.

\section{DATA ANALYSIS}

The magnitude of response to a given tastant was calculated as the mean firing rate (spike per second; sps) during the first $2 \mathrm{~s}$ of tastant delivery minus the average firing rate (sps) during the initial $5 \mathrm{~s}$ of spontaneous activity at the beginning of each trial. Because water was occasionally found to produce a sustained response in a subset of cells, the response to water was not used as a baseline. A taste response was considered to be significant if it was 2.5 standard deviations greater than the average spontaneous firing rate. All cells were classified by their "best stimulus", defined as the tastant that elicits the highest response magnitude. Pre- and post-tastant water responses were calculated by subtracting the mean spontaneous firing rate from the firing rate during the initial $2 \mathrm{~s}$ of the pre- and post-tastant water delivery, respectively. The response magnitude to water was calculated before and after delivery of each of the other taste stimuli.

The breadth of tuning of taste-responsive cells was calculated with both the traditional Uncertainty measure (Smith and Travers, 1979) and the Selectivity measure (Rosen and Di Lorenzo, 2009), a metric designed to capture both breadth of tuning and magnitude of response. The formula for Uncertainty was $H=-k \Sigma P_{i}\left(\log P_{i}\right)$, where $k$ (scaling factor) $=1.66$ for four stimuli and $P_{i}$ is the proportion of response to stimulus $i$ relative to the summed responses to all four taste stimuli. Values ranged from 0 to 1.0 with 0 corresponding to a cell responsive to only one stimulus and 1.0 corresponding to a cell equally responsive to all four stimuli. Selectivity was defined as the difference in response magnitude (in sps) between the sum of the two strongest responses and the sum of the two weakest responses (Rosen and Di Lorenzo, 2009).

\section{RESULTS}

\section{GENERAL RESPONSE CHARACTERISTICS}

The responses to water and taste stimuli were recorded from 135 cells (91 NTS cells; $44 \mathrm{PbN}$ cells), most with several stimulus trial repetitions: In the NTS there were 1-17 stimulus repetitions, median $=8$; in the $\mathrm{PbN}$ there were $1-26$ stimulus repetitions, 
median $=8$. Thirty of 91 NTS cells $(33 \%)$ and 17 of $44 \mathrm{PbN}$ cells (39\%) responded to water, either preceding or following a taste stimulus. There were four types of water responses. Three were categorized as water-responsive and one categorized as somatosensory. The four response types (shown in Figure 1) were: (1) "Water-excitatory" These cells showed water response magnitudes that were equal or greater than the magnitudes of response to all four prototypical taste stimuli $(n=12)$. Ten of these cells showed a larger response to water than to other taste stimuli. These were called "water best" cells. Of these, four responded only to water and were called "water specialist" cells. Of the remaining two cells that showed excitatory water responses, one was $\mathrm{NaCl}$ best and the other was quinine best. (2) "Water-inhibitory" These cells showed a significant decrease in spontaneous firing rate in response to

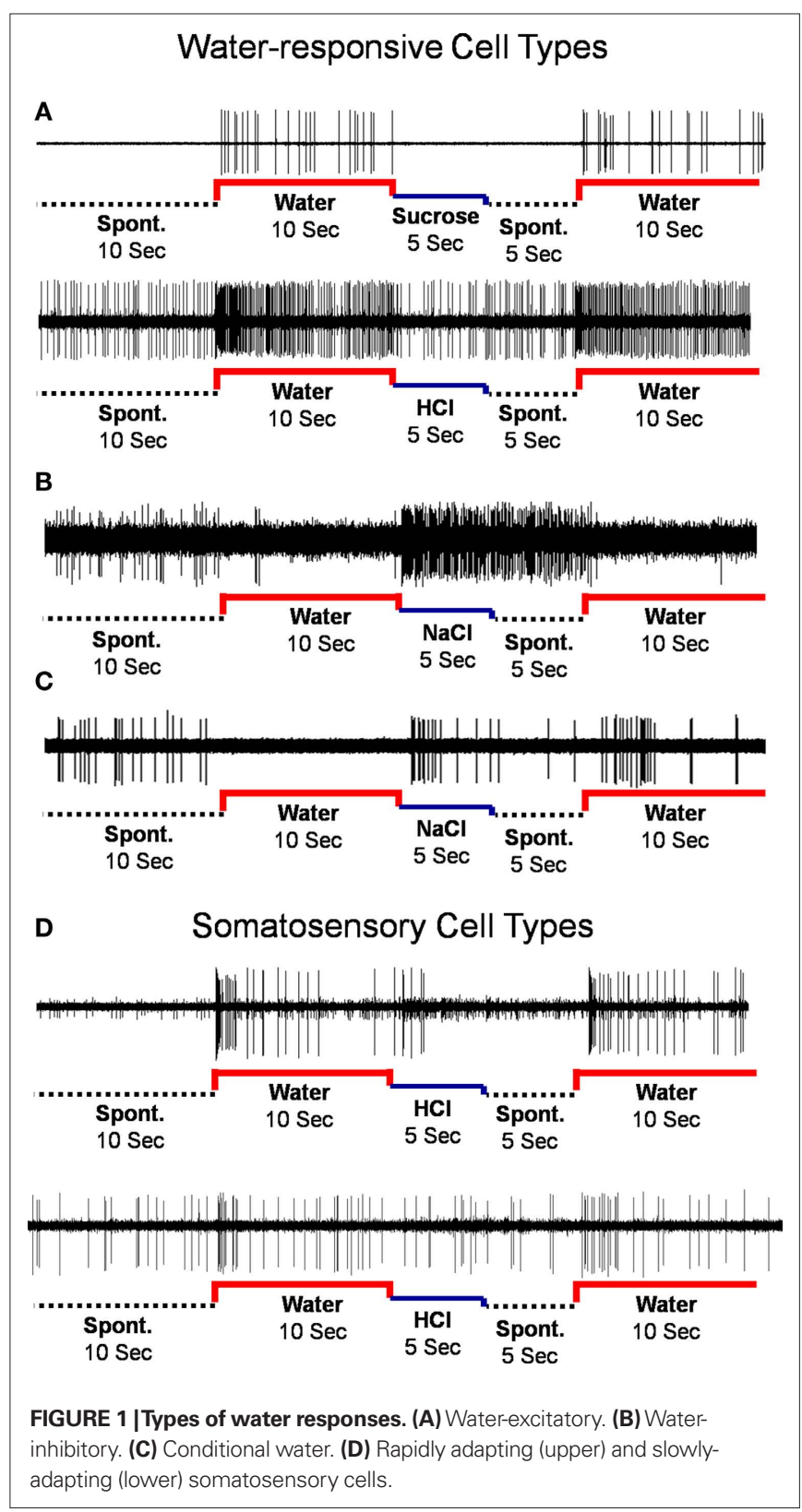

water $(n=2)$. (3) "Conditional water" These cells responded to water, either with excitation or inhibition but showed significantly larger responses to water delivered after a subset of taste stimuli $(n=22)$. (4) "Somatosensory water" These cells showed excitation or inhibition in response to water and an equivalent response to at least some taste stimuli $(n=11)$. We classified these responses as somatosensory because it could be argued that the responses to water could be interpreted as tactile.

\section{WATER-RESPONSIVE CELL TYPES}

The distribution of cells showing each type of water response in the NTS and $\mathrm{PbN}$ is shown in Table 1. Several aspects of this table are noteworthy. For example, water-inhibitory cells were observed only in the NTS, but the prevalence of conditional water cells in the NTS (15 of $30 ; 50 \%$ ) and $\mathrm{PbN}$ (7 of $17 ; 41 \%$ ) was similar. Importantly, there was only one somatosensory cell in $\mathrm{PbN}$ (of 17,6\%) compared with 20 in NTS (of 30; 67\%). Table 1 shows response magnitudes for all stimuli and all cell types.

Water best cells $(n=10)$ constitute our strongest evidence that the taste of water is processed by a separate coding channel. Among these, there were four cells that were water specialists in that they responded only to water and not to any taste stimulus. Figure 2 shows the responses to water and the four prototypical taste stimuli in a water best cell recorded in the $\mathrm{PbN}$. It can be seen that water presented both before and after a tastant, evoked a large excitatory response with a phasic-tonic time course. Presentation of $\mathrm{HCl}$ also evoked an excitatory response, but it was much smaller than that to water. In contrast, presentation of sucrose, $\mathrm{NaCl}$ or quinine evoked a return to spontaneous firing rates.

Figure 3 shows the average response magnitudes of NTS and $\mathrm{PbN}$ cells to water, sucrose, $\mathrm{NaCl}, \mathrm{HCl}$, and quinine for all cells. The responses to water in the $\mathrm{PbN}$ cells were significantly higher than responses to water in NTS $[t(43)=3.2, p<0.01]$. There was no significant difference in the breadth of tuning of NTS and PbN cells as assessed by both the Uncertainty and Selectivity measures. The mean $H$ values were $0.79 \pm 0.05$ and $0.77 \pm 0.04$ for NTS cells and $\mathrm{PbN}$ cells, respectively. The mean Selectivity values were $15.3 \pm 3.6$ and $19.2 \pm 3.8$ for NTS cells and PbN cells, respectively. The mean spontaneous activity of cells in the NTS $(3.7 \pm 0.8)$ and $\mathrm{PbN}(3.9 \pm 1.2)$ also did not significantly differ.

The responses to water before and after each of the four prototypical taste qualities are shown in Figure 4. Tastant delivery altered water responsivity in a stimulus specific manner in all 22 cells that showed conditional water responses. It can be seen that water responses following a taste stimulus could either increase or decrease with respect to the water response just preceding that tastant. Furthermore, conditional water responses were found for every taste stimulus in some subset of cells and were equally common in NTS and PbN.

Table 2 compares the water-responsive cell types in NTS and $\mathrm{PbN}$ with respect to which taste stimulus elicited the best response. Notably, most conditional water responses were found in $\mathrm{NaCl}$ or $\mathrm{HCl}$ best cells in NTS and in $\mathrm{NaCl}$ best cells in $\mathrm{PbN}$.

The water responses of conditional water cells were specific to the taste stimulus that immediately preceded water delivery. The particular taste stimuli that resulted in conditional water responses differed between the NTS and PbN (see Table 3). It can be seen 
Table 1 | Mean responses \pm SEM for water and all taste stimuli in water-response cell types.

\begin{tabular}{|c|c|c|c|c|c|}
\hline & Excitatory & Conditional & Inhibitory & Somatosensory & Water specialist \\
\hline \multicolumn{6}{|l|}{ NTS $(n=30)$} \\
\hline Prevalence & $n=1 ; 3 \%$ & $n=15 ; 50 \%$ & $n=2 ; 7 \%$ & $n=10 ; 33 \%$ & $n=2 ; 7 \%$ \\
\hline Water (pre) & 1.8 & $0.3 \pm 0.6$ & $-4.2 \pm 3.2$ & $2.1 \pm 0.6$ & $8.7 \pm 0.1$ \\
\hline Water (post) & -0.1 & $5.5 \pm 2.6$ & $-5.5 \pm 2.2$ & $1.0 \pm 0.8$ & $1.2 \pm 0.1$ \\
\hline Sucrose & 0.8 & $7.5 \pm 2.6$ & $-1.3 \pm 1.9$ & $4.9 \pm 2.1$ & $0.7 \pm 0.7$ \\
\hline $\mathrm{NaCl}$ & 3.6 & $20.9 \pm 4.2$ & $11.4 \pm 2.0$ & $3.5 \pm 0.8$ & $-0.9 \pm 0.9$ \\
\hline $\mathrm{HCl}$ & 0.8 & $17.6 \pm 5.0$ & $4.5 \pm 0.3$ & $4.0 \pm 1.7$ & $-1.0 \pm 1.0$ \\
\hline Quinine & 1.7 & $15.3 \pm 3.7$ & $2.5 \pm 0.6$ & $1.0 \pm 0.7$ & $-0.6 \pm 2.4$ \\
\hline \multicolumn{6}{|l|}{$\mathrm{PbN}(n=17)$} \\
\hline Prevalence & $n=7 ; 41 \%$ & $n=7 ; 41 \%$ & $n=0$ & $n=1 ; 6 \%$ & $n=2 ; 12 \%$ \\
\hline Water (pre) & $11.6 \pm 3.3$ & $0.4 \pm 1.1$ & NA & 5.6 & $12.9 \pm 10.3$ \\
\hline Water (post) & $10.7 \pm 3.0$ & $5.7 \pm 1.6$ & NA & 5.8 & $11.0 \pm 8.2$ \\
\hline Sucrose & $3.8 \pm 1.0$ & $14.0 \pm 7.0$ & NA & 6.0 & $0.0 \pm 0.1$ \\
\hline $\mathrm{NaCl}$ & $4.8 \pm 1.9$ & $28.4 \pm 7.0$ & NA & 9.4 & $0.6 \pm 0.4$ \\
\hline $\mathrm{HCl}$ & $3.2 \pm 1.9$ & $12.7 \pm 7.0$ & NA & 6.0 & $0.0 \pm 0.4$ \\
\hline Quinine & $11.5 \pm 6.7$ & $13.8 \pm 3.2$ & NA & 14.9 & $0.3 \pm 0.2$ \\
\hline
\end{tabular}

\section{Excitatory Water Responses}
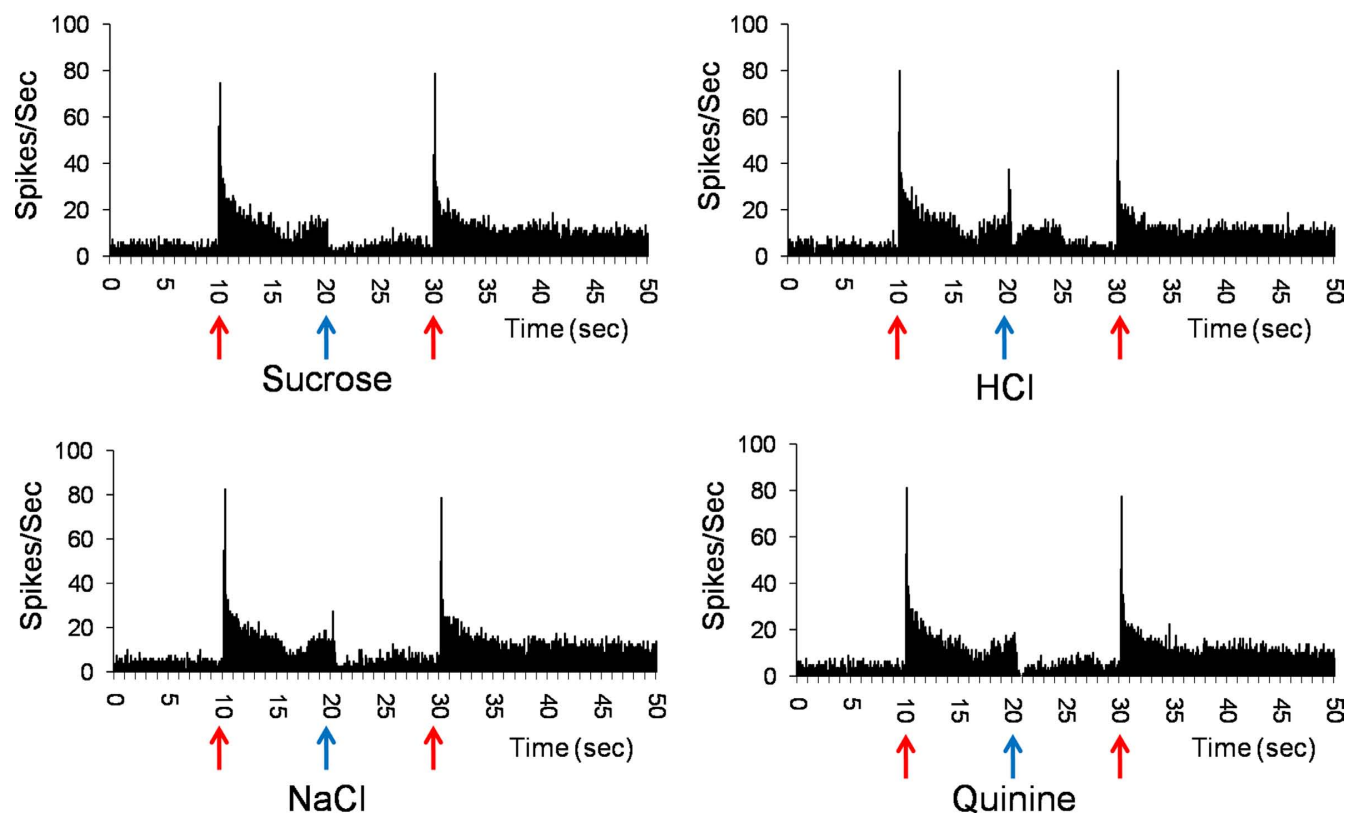

FIGURE 2 | Peristimulus time histograms showing the responses of a $\mathrm{PbN}$ water best cell to water (solid red arrows) and sucrose, $\mathrm{NaCl}$, $\mathrm{HCl}$, and quinine (blue arrows). Shown are eight stimulus presentations superimposed for each histogram.

that any taste stimulus could be followed by a conditional water response. In the NTS, the largest increase in water responsivity was observed when water followed $\mathrm{HCl}$ but in the $\mathrm{PbN}, \mathrm{NaCl}$, and quinine produced the largest increases in water response.

Water-inhibitory cells, found only in the NTS, showed significant decreases in spontaneous activity when water was presented both before and after the delivery of another tastant. These two cells both responded best to $\mathrm{NaCl}$. Figure 5 shows a response to sucrose and to $\mathrm{NaCl}$ in the two inhibitory-water cells. In Figure 5A, water significantly reduced spontaneous activity to near zero while sucrose evoked a return to spontaneous firing rate. In this cell, $\mathrm{NaCl}$ evoked a brief response followed by a return to spontaneous firing rates (Figure 5B).

\section{DISCUSSION}

Water delivered to the oropharyngeal cavity evoked activity in a diverse group of neurons in the NTS and $\mathrm{PbN}$, the first and second central gustatory relays. About a third of cells in each structure (30 


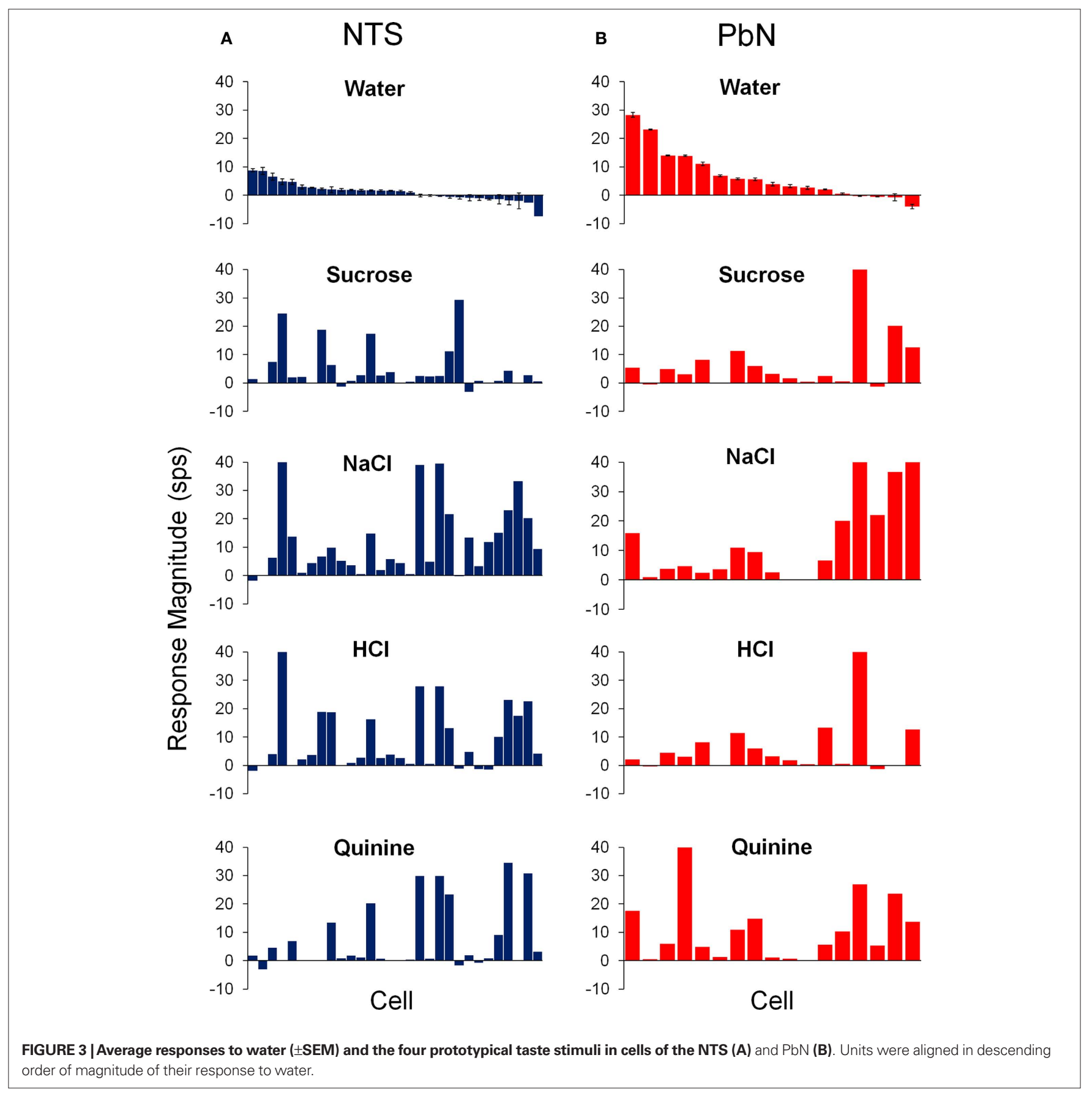

of $91,33 \%$ in the NTS; 17 of $44,39 \%$ in the $\mathrm{PbN}$ ) responded to water either preceding or following a taste stimulus. Three water responsive cell types were observed in both the NTS and $\mathrm{PbN}$. These were excitatory, including water specialists, inhibitory, and conditional. Both excitatory and inhibitory responses to water when presented alone and/or following a taste stimulus were seen. The majority of cells that showed excitatory responses to water, found almost exclusively in the $\mathrm{PbN}$, actually responded more to water than to any taste stimulus. Four cells were water specialists, responding exclusively to water. In conditional water cells, water responses were significantly higher after delivery of a subset of taste stimuli. A separate group of cells were classified as "somatosensory" because they responded equivalently to all water and taste stimuli. These findings, along with data from the existing literature, provide evidence for the idea that water is encoded by a separate information "channel" that begins in the taste receptor and is transmitted through the gustatory neuraxis along with information about other taste stimuli. The view that water is an independent taste modality is consistent with the idea that the function of the gustatory system is to detect and identify chemical stimuli that are essential for survival. 


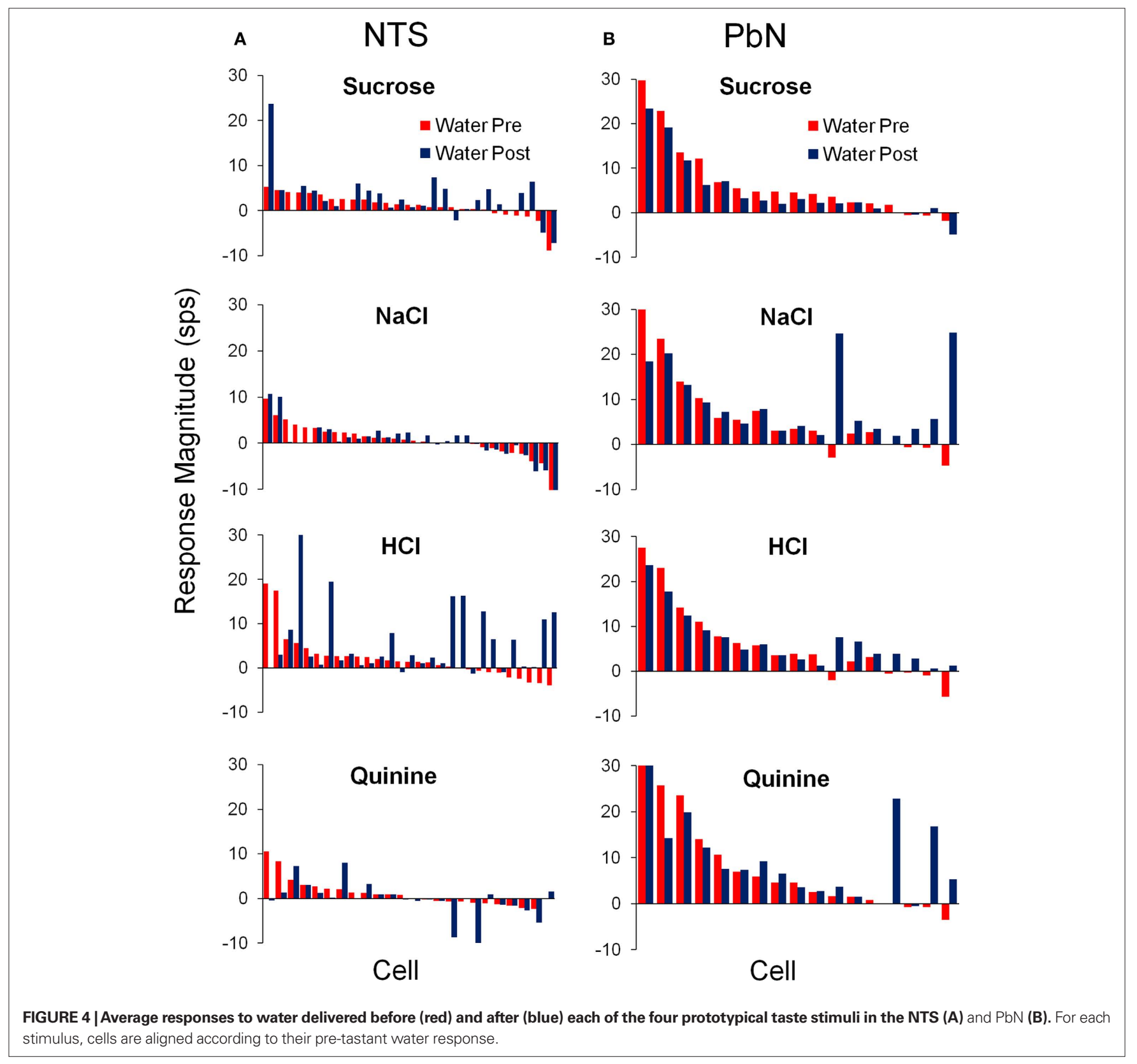

\section{WATER AS AN INDEPENDENT TASTE MODALITY}

As support for the classification of water as an independent taste quality, we argue three lines of evidence. First, the existence of a discrete and dedicated transduction mechanism for water in the oropharyngeal cavity provides a basis for peripheral sensitivity underlying central neural responses. Second, electrophysiological responses in dedicated (specialist, i.e., exclusively responsive to a single taste quality) taste-related peripheral nerves argue that the sensation of water is transmitted to the central nervous system over a separate information channel. Third, data showing responses in water specialist cells in central gustatoryrelated structures provide strong evidence that the central representation of water is distinct from that associated with other taste qualities.
Recently, a dedicated transduction mechanism for water (or hypo-osmolarity), has been identified in the mammalian oropharyngeal cavity. Water enters directly into the taste receptor cell through a channel called an aquaporin (Watson et al., 2007). Several types of aquaporins are expressed by taste receptor cells including AQP5, which is expressed on the apical membrane, and AQP1 and AQP2 which are expressed on the basolateral membrane (Gilbertson et al., 2006). When water enters taste receptor cells they swell. This activates volume-regulated anion channels and results in cell depolarization (Gilbertson, 2002; Gilbertson et al., 2006). Depolarization leads to activation of voltage-sensitive calcium channels that facilitate neurotransmitter release (Gilbertson et al., 2006). Thus a mechanism exists in mammals for transduction of water, apart from other taste stimuli. 
Table 2 | Prevalence of the "best stimulus" for each cell type in the NTS and $\mathrm{PbN}$.

\begin{tabular}{lllll}
\hline & Excitatory & Conditional & Inhibitory & Somatosensory \\
\hline NTS & & $n=15$ & $n=2$ & $n=10$ \\
Sucrose & 0 & $1(7 \%)$ & 0 & $3(30 \%)$ \\
$\mathrm{NaCl}$ & 0 & $6(40 \%)$ & $2(100 \%)$ & $4(40 \%)$ \\
$\mathrm{HCl}$ & 0 & $7(46 \%)$ & 0 & $1(10 \%)$ \\
Quinine & 0 & $1(7 \%)$ & 0 & $1(10 \%)$ \\
Water & $3(100 \%)$ & 0 & 0 & $1(10 \%)$ \\
PbN & & & & \\
& $n=9$ & $n=7$ & $n=0$ & $n=1$ \\
Sucrose & 0 & $1(14 \%)$ & 0 & 0 \\
NaCl & 0 & $5(72 \%)$ & 0 & 0 \\
$\mathrm{HCl}$ & 0 & $1(14 \%)$ & 0 & 0 \\
Quinine & $1(11 \%)$ & 0 & 0 & $1(100 \%)$ \\
Water & $8(89 \%)$ & 0 & 0 & 0
\end{tabular}

Table 3 | Incidence of conditional response following each taste stimulus.

\begin{tabular}{lll}
\hline & NTS $(\boldsymbol{n}=\mathbf{1 5})$ & PbN $(\boldsymbol{n}=\mathbf{7})$ \\
\hline $\mathrm{S}$ & $2(13 \%)$ & 0 \\
$\mathrm{H}$ & $6(40 \%)$ & $1(14 \%)$ \\
$\mathrm{Q}$ & 0 & $1(14 \%)$ \\
$\mathrm{S} / \mathrm{H}$ & $5(33 \%)$ & 0 \\
$\mathrm{~S} / \mathrm{Q}$ & $1(7 \%)$ & 0 \\
$\mathrm{~N} / \mathrm{H}$ & 0 & $2(29 \%)$ \\
$\mathrm{N} / \mathrm{Q}$ & $1(7 \%)$ & $1(14 \%)$ \\
$\mathrm{N} / \mathrm{H} / \mathrm{Q}$ & 0 & $2(29 \%)$ \\
MEAN SPIKE DIFFERENCE (SPS) & \\
$\mathrm{S}$ & $6.5 \pm 1.8$ & $\mathrm{NA}$ \\
$\mathrm{N}$ & 4.1 & $14.1 \pm 6.0$ \\
$\mathrm{H}$ & $15.3 \pm 3.7$ & $5.7 \pm 1.1$ \\
$\mathrm{Q}$ & $4.5 \pm 1.5$ & $16.4 \pm 4.1$
\end{tabular}

Water is also an effective stimulus in peripheral nerves that respond to more traditional taste qualities. Specifically, water responses have been observed in the chorda tympani nerve (a branch of the facial nerve innervating taste buds on the rostral $2 / 3$ of the tongue) of the rat, cat, and dog (Pfaffmann and Bare, 1950; Liljestrand and Zotterman, 1954; Zotterman, 1956), superior laryngeal nerve (a branch of the vagus nerve innervating taste buds on the palate) of the rat (Shinghai, 1980; Hanamori, 2001) and glossopharyngeal nerve (innervating taste buds on the caudal $1 / 3$ of the tongue) of the frog, hamster, and rat (Zotterman, 1949; Hanamori et al., 1988; Frank, 1991). Water specialist fibers have been observed in the superior laryngeal nerve (Shinghai, 1980), a nerve that plays an important role in swallowing (Kitagawa et al., 2009). Interestingly, water applied to the posterior tongue/larynx in humans was shown to be particularly effective at evoking a swallowing reflex as compared to other taste stimuli (Shinghai et al., 1989). In addition, many neurons in the intermediate NTS that mediate swallowing have been shown to receive convergent input from the superior laryngeal and glossopharyngeal nerves (Ootani et al., 1995). In sum, water-responsive fibers have been described in several gustatory nerves and may play a role in the swallowing reflex.

Water-specific responses have also been observed in many gustatory processing regions of the brain including the NTS (Nakamura and Norgren, 1991), PbN (Nishijo and Norgren, 1990), thalamus (Verhagen et al., 2003), and gustatory cortex (de Araujo et al., 2003). These responses, though widely observed, are seldom described in detail. In the current investigation, we extend these observations by describing responses to water elicited in cells of the NTS and $\mathrm{PbN}$. Though some of these responses may be due to tactile or thermal stimulation, we detail some responses for which these explanations are inadequate. Based on this evidence, we argue that the neural representation of water parallels that of more traditional taste qualities.

In addition to the role of water in evoking a swallowing reflex, the perceptual consequences of water taste may play a critical role in regulating fluid intake (thirst) and the maintenance of hydration. The responses described here were recorded with passive

\section{Inhibitory Water Responses}
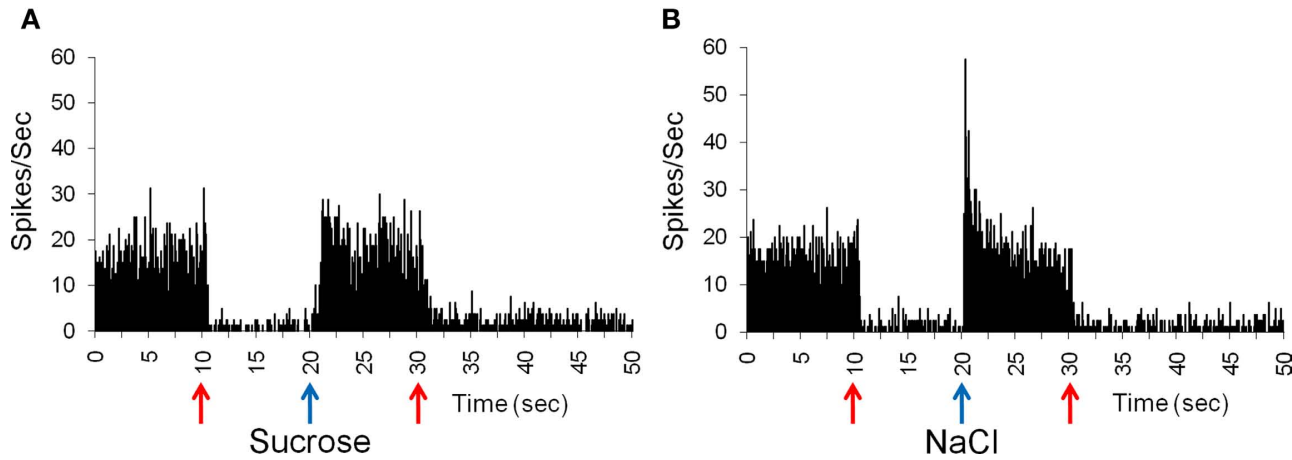

FIGURE 5 | Inhibitory responses to water before and after taste delivery in one cell. This cell is inhibited by water and does not respond to sucrose, as indicated by a return to spontaneous firing rate $(\mathbf{A})$, but shows a brief response to $\mathrm{NaCl}(\mathbf{B})$. Mean spontaneous firing rate for the cell was $12.5 \pm 2.4$ sps. 
stimulus delivery in a non-deprived state and in the absence of post-ingestional effects. It is possible, however, that homeostatic variables such as thirst may modulate the responses to water. For example, in an imaging study of thirst and water taste processing in the human gustatory cortex, the primary gustatory cortex (anterior insula and frontal operculum) was activated by water regardless of thirst but the secondary gustatory cortex (caudal orbitofrontal cortex) only showed water-evoked activation in a water-deprived state (de Araujo et al., 2003). The most likely source of this waterselective cortical activation is taste-related structures that receive input from the oropharyngeal area. The ability of cortical neurons to distinguish between water and other tastes supports the idea that water may be processed as an independent taste quality.

In addition to oral sensitivity, water may also be detected by chemoreceptors located in the gut (Rozengurt and Sternini, 2007). Chemical transduction in the enteric nervous system plays an important role in gut motility, the regulation of nutrient absorption, gastric emptying and acid secretion (Baggio and Drucker, 2007). The vago-vagal reflex, essential for digestives processes such as gastric emptying, involves vagal projections to NTS and from there to the dorsal motor nucleus of the vagus which extends efferents that mediate gastric function (McCann and Rogers, 1992; Konturek et al., 2004). The gastric and intestinal mucosa is sensitive to both mechanical and chemical stimulation (Cottrell and Iggo, 1984). Studies have characterized modality specific enteroreceptors for sugars, acids, fats, amino acids as well as water (Iggo, 1957; Mei, 1978; Jeanningros, 1982; Mei and Garnier, 1986). Endocrine cells of the luminal tissue transduce mechanical and chemical stimuli via paracrine activation of vagal afferents which synapse in the caudal NTS (Zhu et al., 2001; Young et al., 2008) and spinal afferents which synapse in the dorsal horn of the spinal cord (Konturek et al., 2004). Stimulation of the small intestine of the cat with various chemical solutions has shown that water evokes large responses in the nodose ganglion containing cells of the vagus nerve (Mei and Garnier, 1986).

\section{WATER-RESPONSIVE AND SOMATOSENSORY CELL TYPES}

The idea that the taste of water is independent from that of other taste qualities represents a substantial departure from the conventional supposition that water responses are entirely somatosensory. Present data support a clear distinction between water-responsive and somatosensory cell types. Somatosensory cells appeared to respond only to the mechanical and/or thermal components of a fluidic stimulus. That is, their responses to water and tastants were indistinguishable. As can be seen in Figure 1, some of these responses were phasic, suggesting rapid adaptation, and others were more tonic, suggesting slow adaptation. The presence of somatosensory cells is not surprising given the fact that most taste-responsive cells in both NTS and PbN receive convergent mechanosensory input (Ogawa and Kaisaku, 1982; Ogawa et al., 1982, 1984; Ogawa and Hayama, 1984). In contrast, cells identified as water-responsive in the present study showed responses to water that could not be accounted for by the mechanosensory aspects of the stimulus. For example, water best cells responded more vigorously to water than to any of the four other taste stimuli even though all stimuli would be expected to evoke equivalent tactile and thermal sensations. It is possible, perhaps likely, that responses in these cells reflect the osmolarity of the solution, with water being the most hypo-osmotic. In effect, these cells might respond to taste stimuli as a mixture of water and taste stimulus, with water being the effective stimulus that drives neural activity. Water-inhibitory and conditional water cells showed water-specific inhibitory responses that could be predicted by the taste stimulus that preceded water presentation. In this case, an interaction of tastant and water, likely peripheral in nature (Bartoshuk, 1977), might be at play in these cells. In fact, it is well known that water presented after some taste stimuli, usually acid, induce tastes of their own (e.g., Oakley, 1985).

\section{COMPARISON OF NTS AND PbN WATER RESPONSIVITY}

In general, differences between the NTS and $\mathrm{PbN}$ suggest that water sensibility may serve different functions in each structure. In the NTS, the relatively large proportion of somatosensory responses to water may be part of neural circuits extending from the caudal NTS that produce ingestive reflexes such as swallowing (Lang, 2009). In contrast, the significantly higher water-evoked firing rates in the $\mathrm{PbN}$ suggest that the $\mathrm{PbN}$ may be part of the chemosensory pathway for the perception of water along with other taste stimuli.

The sensitivity of gustatory NTS cells to water may play an essential role in the initiation of swallowing. The superior laryngeal nerve of the rat includes water-selective fibers (Shinghai, 1980) and has been shown to converge with the glossopharyngeal nerve onto neurons that mediate swallowing in the intermediate NTS (Ootani et al., 1995). Neurons in the rostral and ventral NTS project caudally to the intermediate NTS (Streefland and Jansen, 1999) which contains premotor neurons that initiate swallowing when water is applied to the pharynx (Lang, 2009). Physiological and behavioral evidence suggests that the chemosensory properties of water may be important in eliciting the swallowing reflex. For example, water has been shown to be an exceptionally effective stimulus for eliciting a swallowing reflex when applied to the pharynx and larynx (Storey, 1968; Shinghai et al., 1989). The extensive connectivity of the rostral NTS with the intermediate NTS, reticular formation and various oromotor nuclei may facilitate swallowing and other taste and somatosensory-mediated ingestive reflexes. Only about a third of NTS cells project directly to the PbN in rat (Ogawa and Kaisaku, 1982; Ogawa and Hayama, 1984; Monroe and Di Lorenzo, 1995), therefore at least some $\mathrm{PbN}$ activity may reflect taste processing that is independent of NTS input (see Di Lorenzo et al., 2009). Gustatory and hepatic-vagal afferents have been shown to converge to a greater degree in the postero-medial $\mathrm{PbN}$ as compared to the NTS (Hermann et al., 1983). Vagal fibers innervating luminal tissue respond robustly to water (Mei and Garnier, 1986) and may therefore contribute to the enhanced water responsivity observed in the $\mathrm{PbN}$.

\section{WATER TASTE AND “AFTER-TASTES"}

Conditional water responses were more prevalent in the NTS than the PbN. This observation suggests that the NTS responses may be more closely tied to peripheral nerve input than the $\mathrm{PbN}$. Psychophysical studies over the last 40 years have emphasized the interdependence of water responses and sensitivity to other taste stimuli. In 1974, Bartoshuk showed that water-evoked a taste but that it was highly dependent on adaptation to a preceding taste stimulus even inclusive of saliva. In addition, recordings from 
afferent taste nerves have shown that some water responses were only observed after pre-exposure to a particular taste stimulus (Bartoshuk and Pfaffmann, 1965; Bartoshuk et al., 1971). These responses were similar to those of the conditional cells reported in the current study, suggesting that responses in these cells directly reflect peripheral processing. The fact that water that follows certain tastes produces a taste sensation of its own implies that these responses to water access the information channels of the taste sensations they evoke as the signal ascends through the central nervous system.

\section{CONCLUSIONS AND CAVEATS}

The present results are not without their limitations. For example, some responses to water may have been affected by the anesthetic under which they were recorded. Urethane anesthesia delivered intraperitoneally (IP), as in the present study, has been shown to produce hyperglycemia, increased hematocrit and decreased blood plasma protein levels (Van Der Meer et al., 1975). Since polydipsia (thirst) is a symptom of hyperglycemia, it is possible that urethane anesthesia could modify responses to water and other taste stimuli.

Sampling errors might also have affected present results. That is, in the recordings of taste responses in both NTS and $\mathrm{PbN}$, most water responses were observed only incidentally.

\section{REFERENCES}

Baggio, L. L., and Drucker, D. J. (2007). Biology of incretins: GLP-1 and GIP. Gastroenterology 132, 2131-2157.

Bartoshuk, L. M. (1974). NaCl thresholds in man: thresholds for water taste or $\mathrm{NaCl}$ taste? J. Comp. Physiol. Psychol. 87, 310-325.

Bartoshuk, L. M. (1977). "Water taste in mammals," in Drinking Behavior, eds J. A. Weijnen and J. Mendelson (New York, NY: Plenum Press), 317-339.

Bartoshuk, L. M., Harned, M. A., and Parks, L. H. (1971). Taste of water in the cat: effects of sucrose on preference. Science 171, 699-701.

Bartoshuk, L. M., and Pfaffmann, C. (1965). Effects of pre-treatment on the water taste response in cat and rat. Fed. Proc. 24, 207.

Chang, F. C., and Scott, T. R. (1984). Conditioned taste aversions modify neural responses in the rat nucleus tractus solitarius. J. Neurosci. 4, 1850-1862.

Cottrell, D. F., and Iggo, A. (1984). Mucosal enteroreceptors with vagal afferent fibres in the proximal duodenum of sheep. J. Physiol. 354, 497-522.

de Araujo, I. E. T., Kringelback, M. L., Rolls, E. T., and McGlone, F. (2003). Human cortical responses to water in the mouth, and the effects of thirst. J. Neurophysiol. 90, 1865-1876.

Di Lorenzo, P.M., Platt, D., and Victor,J. D. (2009). Information processing in the parabrachial nucleus of the pons. Ann. N. Y. Acad. Sci. 1170, 365-371.
Evans, D. R., and Mellon, D. Jr. (1962). Electrophysiological studies of a water receptor associated with the taste sensilla of the blowfly. J. Gen. Physiol. 45, 487-500.

Frank, M. E. (1991). Taste-responsive neurons of the glossopharyngeal nerve of the rat. J. Neurophysiol. 65, 1452-1463.

Ganchrow, J.R., and Erickson, R.P. (1970). Neural correlates of gustatory intensity and quality. J. Neurophysiol. 33, 768-783.

Gilbertson, T. A. (2002). Hypoosmotic stimuli activate a chloride conductance in rat taste cells. Chem. Senses 27, 383-394.

Gilbertson, T. A., Baquero, A. F., and Spray-Watson, K. J. (2006). Water taste: the importance of osmotic sensing in the oral cavity. J. Water Health 4(Suppl. 1), 35-40.

Hanamori, T. (2001). Effects of various ion transport inhibitors on the water response in the superior laryngeal nerve in rats. Chem. Senses 26, 897-903.

Hanamori, T., Miller, I. J. Jr., and Smith, D. V. (1988). Gustatory responsiveness of fibers in the hamster glossopharyngeal nerve. J. Neurophysiol. 60, 478-498.

Hermann, G. E., Kohlerman, N. J., and Rogers, R. C. (1983). Hepatic-vagal and gustatory afferent interaction in the brainstem of the rat. J. Auton. Nerv. Syst. 9, 477-495.

Iggo, A. (1957). Gastric mucosal chemoreceptors with vagal afferent fibres

That is, water responses were only noted "after the fact", when analyses of responses to other tastants were analyzed. It is therefore possible that we missed some cells that might have been responsive to water. Even so, our evidence, and those of others who have described water responses, clearly suggests that the neural representation of water in the chemosensory pathway is weaker than that of other taste qualities. On the other hand, the consistent presence of water responses in almost every electrophysiological study of taste, including the present one, implies that sensibility to water is clearly present and may serve an important purpose.

In conclusion, we have described responsivity to water in two brainstem nuclei, the NTS and PbN, in the anesthetized rat. A novel finding of the current study is the observation of water best neurons and water specialist cells in both NTS and $\mathrm{PbN}$. Importantly, these data underscore the literature showing that water is processed by cells in gustatory nuclei. This implies that water evokes a gustatory sensation that is supported by an independent neural representation, different from that of other taste qualities.

\section{ACKNOWLEDGMENTS}

This work was supported by NIDCD Grants DC-06914 and DC-005219 to P. M. Di Lorenzo.

in the cat. Q. J. Exp. Physiol. 42, 398-409.

Inoshita, T., and Tanimura, T. (2006). Cellular identification of water gustatory receptor neurons and their central projection pattern in Drosophila. Proc. Natl. Acad. Sci. U.S.A. 103 1094-1099.

Jacobs, K. M., Mark, G. P., and Scott, T. R. (1988). Taste responses in the nucleus tractus solitarius of sodium deprived rats. J. Physiol. 406, 393-410.

Jeanningros, R. (1982). Vagal unitary responses to intestinal amino acid infusions in the anesthetized cat: a putative signal for protein induced satiety. Physiol. Behav. 28, 9-21.

Kitagawa, J., Nakagawa, K., Hasegawa, M. Iwakami, T., Shinghai, T., Yamada, Y., and Iwata, K. (2009). Facilitation of reflex swallowing from the pharynx and larynx. J. Oral Sci. 51, 167-171.

Konturek, S. J., Konturek, J. W., Pawlik, T., and Brzozowki, T. (2004). Braingut axis and its role in the control of food intake. J. Physiol. Pharmacol. 55, 137-154.

Lang, I. M. (2009). Brain stem control of the phases of swallowing. Dysphagia 24, 333-348.

Liljestrand, G., and Zotterman, Y. (1954). The water taste in mammals. Acta Physiol. Scand. 32, 291-303.

McCann, M. J., and Rogers, R. C. (1992). Impact of antral mechanoreceptor activation of the vago-vagal reflec in the rat: function zonation of responses. J. Physiol. 453, 401-411.
McCaughey, S. A., Giza, B. K., and Scott, T. R. (1997). Extinction of a conditioned taste aversion in rats: II. Neural effects in the nucleus of the solitary tract. Physiol. Behav. 61, 373-379.

Mei, N. (1978). Vagal glucoreceptors in the small intestine of the cat. J. Physiol. 282, 485-506.

Mei, N., and Garnier, L. (1986). Osmosensitive vagal receptors in the small intestine of the cat. J. Auton. Nerv. Syst. 16, 159-170.

Monroe, S., and Di Lorenzo, P. M. (1995). Taste responses in neurons in the nucleus of the solitary tract that do and do not project to the parabrachial nucleus of the pons. J. Neurophysiol. 74, 249-257.

Morton, G. J., Cummings, D. E., Baskin, D. G., Barsh, G. S., and Schwartz, M. W. (2006). Central nervous system control of food intake and body weight. Nature 443, 289-295.

Nakamura, K., and Norgren, R. (1991). Gustatory responses of neurons in the nucleus of the solitary tract of behaving rats. J. Neurophysiol. 66 , 1232-1248.

Nishijo, H., and Norgren, R. (1990). Responses from parabrachial gustatory neurons in behaving rats. $J$. Neurophysiol. 63, 707-724.

Oakley, B. (1985). Taste responses of human chorda tympani nerve. Chem. Senses 10, 469-481.

Ogawa, H., and Hayama, T. (1984). Receptive fields of solitario-parabrachial relay neurons responsive to 
natural stimulation of the oral cavity in rats. Exp. Brain Res. 54, 359-366.

Ogawa, H., Hayama, T., and Ito, S. (1982). Convergence of input from tongue and palate to the parabrachial nucleus neurons of rats. Neurosci. Lett. 28, 9-14.

Ogawa, H., Imoto, T., and Hayama, T. (1984). Responsiveness of solitarioparabrachial relay neurons to taste and mechanical stimulation applied to the oral cavity in rats. Exp. Brain Res. 54, 349-358.

Ogawa, H., and Kaisaku, J. (1982). Physiological characteristics of solitario-parabrachial relay neurons with tongue afferent inputs in rats. Exp. Brain Res. 48, 362-368.

Ogawa, H., Yamashita, S., and Sato, M. (1974). Variation in gustatory nerve fiber discharge pattern with change in stimulus concentration and quality. $J$. Neurophysiol. 37, 443-457.

Ootani, S., Umezaki, T., Shin, T., and Murata, Y. (1995). Convergence of afferents from the SLN and GPN in cat medullary swallowing neurons. Brain Res. Bull. 37, 397-404.

Pfaffmann, C., and Bare, J. K. (1950). Gustatory nerve discharge in normal and adrenalectomized rats. J. Comp. Physiol. Psychol. 43, 320-324.

Rosen, A. M., and Di Lorenzo, P. M. (2009). Two types of inhibitory influences target different groups of taste-responsive cells in the nucleus of the solitary tract of the rat. Brain Res. 1275, 24-32.

Roussin, A. T., Victor, J. D., Chen, J. Y., and Di Lorenzo, P. M. (2008). Variability in responses and temporal coding of tastants of similar quality in the nucleus of the solitary tract of the rat. J. Neurophysiol. 99, 644-655.

Rozengurt E., and Sternini, C. (2007). Taste receptor signaling in the mammalian gut. Curr. Opin. Pharmacol. 7, 557-562.

Shinghai, T. (1980). Water fibers in the superior laryngeal nerve of the rat. Jpn. J. Physiol. 30, 305-307.

Shinghai, T., Miyaoka, Y., Ikarashi, R., and Shimada, K. (1989). Swallowing reflex elicited by water and taste solutions in humans. Am. J. Physiol. Regul. Integr. Comp. Physiol. 256, 822-826.

Smith, D. V., and Travers, J. B. (1979). A metric for the breadth of tuning of gustatory neurons. Chem. Senses 4, 215-229.

Storey, A. T. (1968). Laryngeal initiation of swallowing. Exp. Neurol. 20, 359-365.

Streefland, C., and Jansen, K. (1999). Intramedullary projections of the rostral nucleus of the solitary tract in the rat: gustatory influences on autonomic output. Chem. Senses 24, 655-664.

Van Der Meer C., Versluys-Broers, J. A., Tuynman, H. A., and Buur, V. A (1975). The effect of ethylurethane on hematocrit, blood pressure and plasma-glucose. Arch. Int. Pharmacodyn Ther. 217, 257-275.

Verhagen, J.V., Giza, B. K., and Scott, T. R. (2003). Responses to taste stimulation in the ventroposteromedial nucleus of the thalamus in rats. J. Neurophysiol. 89, 265-275.

Watson, K. J., Kim, I., Baquero, A. F., Burks, C. A., Lidong, L., and Gilbertson, T. A. (2007). Expression of aquaporin water channels in rat taste buds. Chem. Senses 32, 411-421.

Young, R. L., Cooper, N. J., and Blackshaw, L.A. (2008). Chemical coding and central projections of gastric vagal afferent neurons. Neurogastroenterol. Motil. 20 708-718.

Zhao, G. Q., Zhang, Y., Hoon, M. A. Chandrashekar, J., Erlenbach, I., Ryba, N. J. P., and Zuker, C. S. (2003). The receptors for mammalian sweet and umami taste. Cell 115, 255-266.

Zhu, J. X., Zhu, X. Y., Owyang, C., and Li, Y. (2001). Intestinal serotonin acts as a paracrine substance to mediate vagal signal transmission evoked by luminal factors in the rat. J. Physiol. 530, 431-442.
Zotterman, Y. (1949). Response of the frog's taste fibers to the application of pure water. Acta Physiol. Scand. 18, 181-189.

Zotterman, Y. (1956). Species differences in the water taste. Acta Physiol. Scand. 37, 60-70.

Conflict of Interest Statement: The authors declare that the research was conducted in the absence of any commercial or financial relationships that could be construed as a potential conflict of interest.

Received: 10 May 2010; accepted: 17 September 2010; published online: 15 October 2010.

Citation: Rosen AM, Roussin AT and Di Lorenzo PM (2010) Water as an independent taste modality. Front. Neurosci. 4:175. doi: 10.3389/fnins.2010.00175

This article was submitted to Frontiers in Autonomic Neuroscience, a specialty of Frontiers in Neuroscience.

Copyright (c) 2010 Rosen, Roussin and Di Lorenzo. This is an open-access article subject to a non-exclusive license between the authors and Frontiers Media $S A$, which permits use, distribution and reproduction in other forums, provided the original authors and source are credited and other Frontiers conditions are complied with. 